\title{
Thyroid Stimulation Test with Serum Thyroxine Concentration as Index of Thyroid Response
}

\author{
E. S. WILlIAMS,* M.B., PH.D. ; R. P. EKINS, $\dagger$ M.A., PH.D. ; S. M. ELLIS $\ddagger$
}

British Medical fournal, 1969, 4, 336-338

Summary : A thyrotropin (T.S.H.) test is suggested $\checkmark$ which relies on the change in the concentration of serum thyroxine as the index of thyroid response to T.S.H. stimulation. Ten such tests have been carried out in healthy volunteers and 39 in patients referred for routine thyroid stimulation tests. Among the advantages of such a test are that the patient does not receive ionizing radiation ; it is independent of the presence of iodideor mercury-containing compounds ; and it minimizes the number of patient visits. In remote areas the patient need not attend the specialist centre, because the T.S.H. injection can be given and the serum samples taken locally, the samples then being sent to the appropriate laboratory for assay.

\section{Introduction}

Over 30 ,years ago it was proposed (Scowen, 1937) that thyrotropin (T.S.H.) might be used in cases of hypothyroidism to investigate the ability of the thyroid gland to respond to stimulation. With the advent of radioactive tracers detailed study of the thyroid by means of radioactive iodine became possible, and in the early 1950s a number of workers established the "T.S.H. test" as an important method of differentiating primary failure of the gland from secondary failure due to pituitary insufficiency (Querido and Stanbury, 1950 ; Perlmutter et al., 1952 ; Perloff et al., 1952 ; Jefferies et al., 1953 ; Schneeberg et al., 1954). The clinical evaluation of the test results and alternative test regimens have more recently been reviewed (Taunton et al., 1965; Fore and Wynn, 1966 ; Burke, 1968).

The first action of T.S.H. on the thyroid is the promotion of hormone release; subsequently it also increases the trapping of plasma iodide by the gland. As commonly applied in routine clinical practice the latter effect is observed by measurement of the uptake of radioactive iodine; conversely, in some centres the release of hormone is indirectly measured by measuring the change in concentration of serum protein-bound iodine (P.B.I.) following T.S.H. injection. Many factors interfere both with thyroid tracer studies and with P.B.I. estimation (Grayson, 1960 ; Thorén, 1960), particularly common ones being prior medication with an iodinated pharmaceutical or administration of $x$-ray contrast media. Certain drugs available for direct purchase by the public fall into this category, and their effect on thyroid function testing may also be prolonged (Sönksen et al., 1968). It therefore appeared worth while to investigate a T.S.H. test based on a criterion of thyroid function which could be accurately assessed in spite of an excess body content of iodide.

\section{Materials and Methods}

Serum thyroxine concentration was measured by means of a specific assay based on the principles of saturation analysis, the thyroxine-binding protein contained in pooled human serum being used as the specific binding agent (Ekins et al., 1969). The thyrotropin used was a commercial preparation
(Thytropar) and each test was carried out with a single intramuscular injection of 10 international units.

A dose of $15-20 \mu \mathrm{Ci}$ of ${ }^{131} \mathrm{I}$ (Radiochemical Centre, Amersham) was administered orally for thyroid uptake studies. The uptake measurements were made with a double Geiger counter system which has been in routine use in this laboratory. for many years, and, though incorporating various improvements, is essentially that described by Tait et al. (1951). The phantom used was made here and has been shown to give results in close agreement with those obtained with the Oak Ridge Institute of Nuclear Studies' mannequin "Moira" and with an International Atomic Energy Agency's phantom when these were each directly compared by means of our thyroid uptake equipment. No correction was made for non-thyroidal neck radioactivity.

Thirty-nine patients were studied, each having been referred for a T.S.H. test as part of a thyroid investigation. In no case was this study carried out on a patient other than when the test was required as an aid in making the final diagnosis. The volunteers (eight men and one woman) were healthy colleagues of ours aged between 28 and 40 years. Tracer studies were not carried out on the volunteers.

The test was conducted as follows: radioactive iodine $\left({ }^{131} \mathbf{I}\right)$ was given orally, and 24 hours later the neck radioactivity was measured and the percentage uptake of the administered tracer calculated in the usual way. Other measurements-for example, that of the serum protein-bound ${ }^{131}$ I 48 hours after administration of the dose-were usually also made, but these are not relevant to the present report. An aliquot of serum was stored in deep-freeze for later thyroxine assay. On the first day of the next series of attendances an intramuscular injection of 10 i.u. of T.S.H. was given ; 24 hours' later the patient's residual neck radioactivity from the earlier tracer dose was measured and a sample obtained for thyroxine assay. A second similar dose of ${ }^{131}$ I was then given, and 24 hours later the thyroidal uptake, suitably corrected for the contribution from the earlier dose, was determined as before. Both the serum obtained before the administration of T.S.H. and that obtained 24 hours after T.S.H. were included in a single assay run to minimize assay errors.

\section{Results}

The serum concentration of thyroxine in the volunteers following the injection of 10 i.u. of T.S.H. is shown in Fig. 1. In one subject the initial response was studied in more detail, and the result is shown in Fig. 2. The overall shape of the curve relating serum thyroxine concentration to time was similar between individuals, but the time for the peak serum concentration to be reached varied from one subject to another. The mean time from T.S.H. injection to peak response was 27.4 hours with a standard deviation (10 studies) of 8.0 hours. The smallest observed response was a peak rise of serum thyroxine of $39 \%$.

\section{* Director.}

$\dagger$ Deputy Director.

$\neq$ Technician

Institute of Nuclear Medicine, Middlesex Hospital Medical School, London W1N 7RL. 
Thirty-nine patients were studied. Serum samples were obtained before and 24 hours after the T.S.H. injection and the 24-hour ${ }^{131}$ I uptake was measured as outlined above. A normal tracer uptake response was taken to be an increase in uptake to at least twice the prestimulation value, or, if this value was very low, to above $15 \%$ of the administered tracer dose. In view of the results of the tests carried out on the healthy volunteers a satisfactory response as measured by the change in serum thyroxine concentration was provisionally taken as a $35 \%$ increase. The uptake and thyroxine responses were in agreement in 33 of the 39 patients, in two a poor uptake response occurred when the thyroxine response was normal, and in four there was a normal uptake response in the presence of a low thyroxine response. No adverse reactions of any sort were recorded among either the patients or the volunteers.

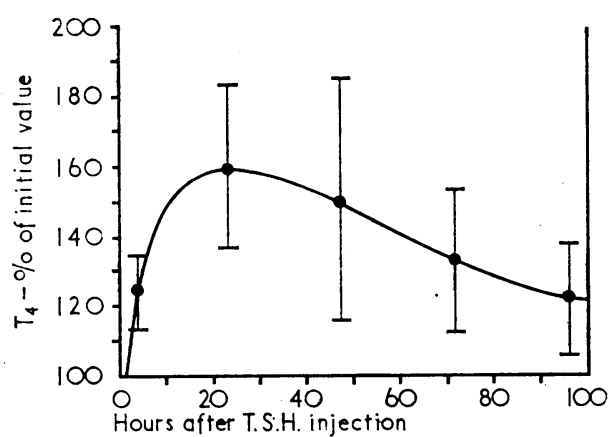

Fig. 1.-Serum concentration of thyroxine following intramuscular injection of 10 i.u. T.S.H. Ten studies of nine healthy subjects. One S.D. is shown.

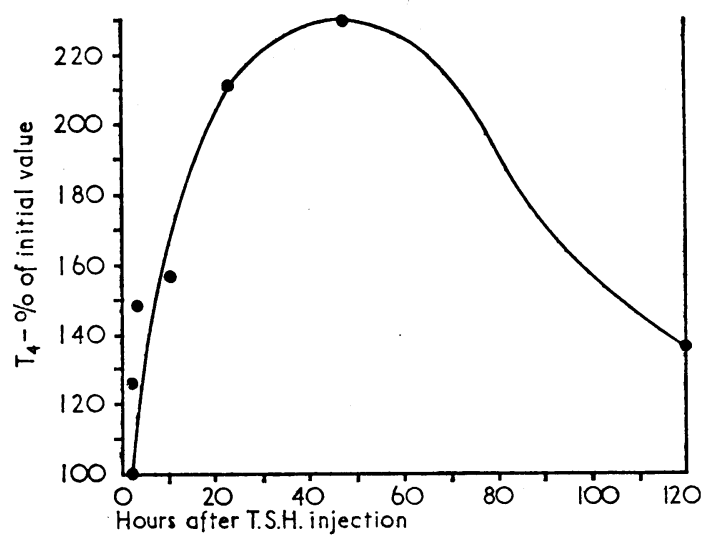

FIG. 2.- -Result of a more detailed study of the serum thyroxine response to the intramuscular injection of $10 \mathrm{i} . \mathrm{u}$. T.S.H. in one healthy subject.

\section{Discussion}

Iodides and iodine-containing drugs interfere both with tracer tests of thyroid function and with estimation of the P.B.I. Excess iodide lowers the uptake of radioactive iodine, and Koutras and Livadas (1965) have shown that as little as $40 \mathrm{mg}$. of potassium iodide is sufficient to inhibit almost completely the uptake of the tracer by the gland $(1 \mathrm{ml}$. of Lugol's solution contains about $130 \mathrm{mg}$. of iodine). There is an opposite effeet on the P.B.I.: it is raised. The duration of such interference is greatly affected by the chemical constitution of the iodine-containing material ; even where the iodine in the molecule is firmly bound in a non-ionizable form degradation within the body ultimately sets iodide ions free to add to the iodide pool. It has been recorded that 33 years after an iodinated dye had been used in a patient the P.B.I. was still abnormally raised (Shapiro and Man, 1960). Moreover, where the same compound had been used in a mother the fetal
P.B.I. was observed to be in excess of $4,000 \mu \mathrm{g} . / 100 \mathrm{ml}$. (Shapiro, 1961). Mercurials depress the P.B.I., giving rise to misleadingly low values. In contrast neither iodide nor mercury affects the $T_{4}$ assay; it is remarkably specific and few interfering substances have been reported (Murphy and Pattee, 1964 ; Murphy et al., 1966 ; Ekins et al., 1969).

Though ${ }^{132} \mathrm{I}$ is used clinically, ${ }^{131} \mathrm{I}$ is much the most commonly used isotope for thyroid investigations, and when administered at the usual dose level there is a far from negligible radiation dose to the thyroid (Werner et al., 1952). In children and in pregnancy such radiation dosage is better avoided, and an index of thyroid function not requiring the exposure of the patient to radiation is to be preferred. In the adult where serial tests are required (Jefferies et al., 1956) the justification for irradiation of the thyroid should be carefully assessed and a test such as the one now proposed be considered instead.

Recent reviewers of the T.S.H. test (Fore and Wynn, 1966 ; Burke, 1968) state that both the tracer uptake response and the P.B.I. response should be used. Where this is thought to be essential it is better to replace the indirect assay of thyroid hormone, the P.B.I. estimation, by the direct, specific $\mathrm{T}_{4}$ assay. Should one wish to compare results so obtained with published work based on P.B.I. studies it is only necessary to multiply P.B.I. values by $100 / 65$ to convert them to $T_{4}$ values, since $65 \%$ of the molecular weight of $\mathrm{T}_{4}$ is due to the four iodine atoms it contains.

Examination of Fig. 1 suggests that the thyroid rapidly releases hormone into the circulation in response to T.S.H. stimulation. The more detailed study recorded in Fig. 2 confirms this. The 90-minute serum value does not differ significantly from the prestimulation value, but serum taken at 143 minutes after T.S.H. injection shows a rise in $\mathrm{T}_{4}$ concentration of $25 \%$ (the within-assay standard deviation of replicate assays is about $5 \%$ ). This rapid action of T.S.H. on the release of hormone from the thyroid is in accord with the many animal studies reported (Field, 1968). Although there is evidence that T.S.H. promotes the preferential release of triiodothyronine $\left(\mathrm{T}_{3}\right.$ ) from the thyroid (Nauman et al., 1967; Wynn, 1967), these results strongly suggest that $T_{4}$ is also significantly released. The $T_{4}$ assay system used is responsive to $T_{3}$, but the energies of reaction of the two compounds with thyroxinebinding globulin are such that, at the reagenit concentrations used, $T_{3}$ is seven to eight times less potent than $T_{4}$; consequently an immense release of $T_{3}$ would be required for this to affect significantly the observed $T_{4}$ value at the concentrations usually recorded.

The pronounced variation between the volunteers in the time taken for the peak $T_{4}$ concentration to be reached makes difficult the preselection of the optimum time to take a single serum sample. The peak of the $\mathrm{T}_{4}$ concentration/time curve was in every case broad, and exact timing was not critical. Thus though the group mean time to peak of about 27 hours may be considered the optimal sampling time, no important error would be introduced in the clinical application of the test if a serum sample were taken about 24 hours after the T.S.H. injection.

Out of the 39 patients studied six gave $T_{4}$ concentration changes which did not accord with the ${ }^{131}$ I uptake changes when the criteria mentioned in the results section were used. Of two patients with poor uptake response but normal $T_{4}$ response one had had a subtotal thyroidectomy 39 years before and at the time of the test had a palpable firm thyroid stump. The initial 24-hour uptake was in the hypothyroid range but the initial concentration of serum $T_{4}$ was normal. The other patient also had an initial $\mathrm{T}_{4}$ value well into the normal range, and the subsequent history throws doubt on the validity of the lack of uptake response to T.S.H. injection. The four patients who had a good uptake response but poor $T_{4}$ response all had initial $T_{4}$ values which themselves would exclude hypothyroidism 
We would like to thank our colleagues who allowed us to carry out studies on them and the members of the consultant staff of the Middlesex Hospital who referred patients to us for investigation and so enabled this work to be carried out.

\section{RBFERENCES}

Burke, G. (1968). Annals of Internal Medicine, 69, 1127. Ekins, R. P., Williams, E. S., and Ellis, S. (1969). Clinical Biochemistry,

Field, J. B. (1968). Metabolism, 17, 226.

Fore, W., and Wynn, J. (1966). American fourmal of Medicine, 40, 90. Grayson, R. R. (1960). American fournal of Medicine, 28, 397.

Jefferies, W. McK. Kelly, L W , Levy, R P Cooper, G W and Prouty, R L, (1956) Foumal of Clinical Endocrinology and Metabolism, 16, 1438 .

Jefferies, W. McK., Levy. R, P., Palmer, W. G., Storassli, I. P., and Kelly, L. W., jun. (1953). New England fournal of Medicine, 249, 876.

Koutras, D. A., and Livadas, D. (1965). Nuclear-Medizin, 5, 256.

Murphy, B. E. P., and Pattee, C. J. (1964). Fournal of Clinical Endocrinology and Metabolism, 24, 187

Murphy, B. E. P., Pattee, C. J., and Gold, A. (1966). Fournal of Clinical Endocrinology and Metabolism, 26, 247.
Nauman, J. A., Nauman, A., and Werner, S. C. (1967). Fournal of Clinical Investigation, 46, 1346.

Perlmutter, M., Weisenfeld, S., Slater, S., Wallace, E. Z., and David, M. M. (1952). Fournal of Clinical Endocrinology and Metabolism, $12,208$.

Perloff, W. H., Levy, L. M., and Despopoulos, A. (1952). Fournal of Clinical Endocrinology and Metabolism, 11, 1495

Querido, A., and Stanbury, J. B. (1950). Fournal of Clinical Endocrinology and Metabolism, 10, 1192.

Schneeberg, N. G., Perloff, W. H., and Levy, L. M. (1954). Fournal of Clinical Endocrinology and Metabolism, 14, 223.

Scowen, E. F. (1937). Lancet, 2, 799.

Shapiro, R. (1961). New England fournal of Medicine, 264, 378.

Shapiro, R., and Man, E. B. (1960). Fournal of the American Medical Association, 173, 1352.

Sönksen, P. H., Ekins, R. P., Stevens, H. G., Williams, E. S., and Nabarro, J. D. N. (1968). Lancet, 2, 425.

Tait, J. F., Cook, J. R., and Worsnop, R. (1951). British fournal of Radiology, 24, 14.

Taunton, O. D., McDaniel, H. G., and Pittman, J. A., jun. (1965). Fournal of Clinical Endocrinology and Metabolism, 25, 266

Thorén, A. (1960). Acta Endocrinologica K申benhavn, 35, 351.

Werner, S. C., Hamilton, H., and Nemeth, M. R. (1952). Fournal of

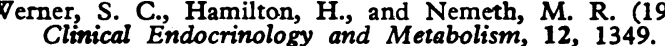

Wynn, J. (1967). 59th Annual Meeting of the American Society for Clinical Investigation, p. 115. Quoted by S. C. Werner and J. A. Nauman, Annual Review of Physiology, 1968, 30, 213

\title{
Thyroid Suppression Test with Serum Thyroxine Concentration as Index of Suppression
}

\author{
E. S. WILlIAMS,* M.B., PH.D. ; R. P. EKINS, † M.A., PH.D. ; S. M. ELLIS $\ddagger$
}

British Medical fournal, 1969, 4, 338-340

Cummary : A thyroid suppression test is suggested which relies on the change in concentration of serum thyroxine as the index of thyroid response to the administration of triiodothyronine. The test has been carried out in 16 healthy volunteers and in 27 patients referred for routine suppression tests. This index appears to be sensitive and safe and results in a reduction in the required dosage of triiodothyronine. The test can be carried out in fewer patient-visits than the commonly used suppression test ; moreover, in remote areas the patient need not attend the specialist centre because the course of triiodothyronine can be given (and the serum samples obtained) locally, the samples then being sent to the appropriate laboratory for assay.

\section{Introduction}

Though Greer and Smith (1954) showed that a comparison of the 24-hour neck uptake of a tracer dose of radioiodine before and after a course of desiccated thyroid afforded a useful method of distinguishing the presence of thyroid autonomy, the suppression test as now normally applied is based on the method of Werner and Spooner (1955), who used triiodothyronine $\left(T_{s}\right)$ as the suppressing agent. Variants from the original report consist in the dosage regimen selected and in the particular measurements used to assess thyroid handling of an iodide tracer. This paper reports a study in which the selected index of thyroid response to the administration of a course of $T_{3}$ is the total serum concentration of thyroxine $\left(T_{4}\right)$.

\section{Materials and Methods}

The serum thyroxine was measured and the ${ }^{131} \mathrm{I}$ uptake into the thyroid was determined as indicated previously (Williams et al., 1969). Twenty-seven patients were studied, those in-

Director.

+ Deputy Director.

$¥$ Technician.

Institute of Nuclear Medicine, the Middlesex Hospital Medical School, London W1N 7RL. cluded in the series being confined to those in whom a suppression test was in any case required on clinical grounds. The volunteers (eight men and eight women) were either our colleagues or staff members of another school of the University of London; they were all healthy and their ages ranged from 23 to 58 years. With one exception, discussed below, tracer studies were not carried out on the volunteers.

The test was conducted as follows. Radioactive iodine ${ }^{(131}$ I) was given orally and 24 hours later the neck radioactivity measured and the percentage uptake of the administered tracer calculated in the usual way. A blood sample was also taken at this time and the serum separated and stored in deep-freeze for later thyroxine assay. The course of $T_{3}$ was then given; in the case of patients this was usually $40 \mu \mathrm{g}$. every eight hours for seven days. Some of the volunteers were also given this dosage but others received $20 \mu \mathrm{g}$ every six hours and others $40 \mu \mathrm{g}$. at eight-hour intervals on alternate days. Immediately after the course of $T_{3}$ a second blood sample was taken for serum thyroxine assay, and, in the patients, the residual neck radioactivity was measured before a second dose of $15-20 \mu \mathrm{Ci}$ ${ }^{131}$ I was given. Twenty-four hours later the percentage thyroid uptake of tracer was again determined. Blood samples for serum thyroxine assay were obtained from the volunteers at intervals during the course of $\mathrm{T}_{3}$ as well as after its completion.

\section{Results}

The inital serum $T_{4}$ concentration in all the volunteers was in the normal range, which in our laboratory is taken to be 45-115 ng./ml. (Ekins et al., 1969). The results presented in each of the figures are expressed as a percentage of this initial concentration, taken as $100 \%$. The serum $\mathrm{T}_{4}$ values during and immediately following the course of $T_{3}$ fell within the shaded area of Fig. 1 in 15 of the 16 volunteers. The exception was a man aged 40 . Fig. 2 shows his serum $T_{4}$ values during two courses of $T_{3}$ separated by three months. When the 24-hour uptake was used as the index, and $40 \mu \mathrm{g}$. $\mathrm{T}_{3}$ was given every eight hours for seven days, only partial suppression occurred. It was subsequently discovered that there is a family 